\title{
Savant Talent
}

\author{
Linda Pring ${ }^{1}$
}

${ }^{1}$ Address for Correspondence: Professor Linda Pring; Psychology Department, Goldsmiths College, University of London, SE14 6NW. email 1.pring@gold.ac.uk 
Acknowledgements: I would like to thank Prof. Beate Hermelin for allowing me to join her research team in 1979 and later for our very enjoyable 15-year research partnership and Dr. Nicola Ryder and Dr. Lisa Heavey for allowing me to use some of their material from their PhD theses. 


\begin{abstract}
The notion of talent is an elusive concept but there appears to be sound evidence that both savants and experts share important qualities Brief descriptive accounts of the talents displayed by savants are presented, along with a discussion of intelligence, implicit learning and the organization of knowledge along with cognitive theories helpful in understanding exceptional abilities in people with autism. It is concluded that a certain cognitive style i.e., weak coherence, may predispose individuals to develop their talents. Although it would be interesting to speculate that some great artists and mathematicians show a similar degree of obsessive preoccupation and a cognitive style reminiscent of autistic spectrum disorder, presumably as a strategic mechanism, there is, as yet, little research on the subject.
\end{abstract}

\title{
Islands of talent
}

The term idiot savant first coined by Down (1) referred to individuals with mental retardation who demonstrated striking abilities or skills against a background of low cognitive functioning. Today such individuals are called savants and the term has been extended to refer to individuals with IQ levels that are potentially in the normal range but with developmental disorders, particularly autism. Treffert (2) distinguished between a talented savant who must possess a level of ability that is remarkable in comparison with their general level of functioning and a prodigious talent, where the displayed ability is exceptional in comparison with the whole population. Howe, Davidson \& Sloboda (3) have suggested that the concept of 'talent' is a myth with high performance arising out of extended practice rather than inherent abilities, though, Rutter (4) amongst others, argues that the very existence of savant ability is, in itself, evidence for innate talent. Before returning to the role of practice and its relationship to memory it may be useful to consider some of the talents that have been the subject of savant research and to describe general features of individuals who show savant talent.

\section{Savant talents}

Savant talent has traditionally involved exceptional memory and sometimes for rather unusual material (e.g. bus routes or telephone directories). The descriptions below highlight more traditional 'talented performance' and serve to give a sketch of the relevant features. 


\section{Music}

Highly organised knowledge structures and complex computations are likely to underpin the skills involved in musical talent and also mathematical and calendrical calculation. For example musical savants have at times been considered comparable to professional musicians and have the ability to transpose music across keys, render imitations of specific musical styles, distinguish constituent tones from chords and have an exceptional memory for music (5). All musical savants described in the literature display absolute pitch which is the ability to recognise, label and remember pitch information without reference to an external standard and is very likely to be critical for the development of savant ability. Possession of absolute pitch may be quite common amongst savants without musical talent, and certainly it has been reported in an artistic savant and calendar calculator $(6,7)$.

\section{Calendar and numerical calculation}

Calendar calculation involves the generation of the appropriate day of the week of a given date, in a matter of only a few seconds. Their calculation spans vary from as little as five years to 40,000 years (8). The feat may at times be overestimated because most people are not aware of the highly structured nature of the Gregorian calendar and the existence of many rules and regularities. For example every 28 years and every 400 years the calendar repeats, and March and November share some calendar configurations so that for example the $1^{\text {st }}$ November will always fall on the same day of the week as $1^{\text {st }}$ March in that year. Nevertheless, amongst a group of calendar calculators whose memory performances are described in Heavey, Pring and Hermelin (8), J.P took only 10 seconds to accurately identify the day of the week for $1^{\text {st }}$ April 1850, and 4.1 seconds for $22^{\text {nd }}$ June 1979 ; M.W. taking 1.9 seconds for $15^{\text {th }}$ December 1964 and H.P. taking 50.8 seconds to calculate the correct response for $7^{\text {th }}$ January 613 AD.

Performance on tests of general short- and long-term memory is not exceptional in contrast to memory for calendar information and this pattern is mirrored in the performance of non-savant chess or physics experts, where an advantage in domainspecific but not domain-general learning and memory skill is displayed (9). 
Numerical calculators are rare and some of those documented have also been able to identify prime numbers (10). It is the lightening speed of the calculation without any aids that make the characteristic performance so remarkable. Testing H.P (mentioned above) on a variety of random arithmetic tests, he could recognise 6907 as a prime in 5.5 seconds and 4517 in 34.7 seconds, could multiply a 3 figure digit by itself (e.g. $\left.476^{2}\right)$ in 21 seconds, 8 seconds for $\left(29^{2}\right)$ and 6 seconds for $\sqrt{ } 841$ !

\section{Language-related}

There are only a very limited number of linguistic savants that have ever been systematically described (11). In terms of second-language learning Christopher has been studied extensively, he can understand and talk in upward of 20 languages drawn from a variety of language groups and Hermelin (12) has suggested that 'his linguistic strength lies primarily in the speedy and correct acquisition of apparently unlimited vocabulary items, as well as the smallest structural parts (morphemes) of new languages'. The studies of Christopher or Katie, a savant poet (13) should be distinguished from explorations of the content and linguistic features of poetry by people with psychotic illnesses (14).

\section{Art}

Although less intuitively obvious artistic talent depends on the understanding of complex geometries in order for the viewed 3-dimensional world to be transcribed on to a 2-dimensional canvas. Savant artists commonly portray linear perspective in their art and this, along with the abandoning of perceptual size constancy, is a key feature in drawing. Accounts of savants with a specific skill in the graphic domain have appeared in the literature since the 1900's and it is possibly the most commonly documented, at least in terms of descriptive accounts. The thumbnail sketches given below characterise most of the essential features of the group. Selfe provided one of the most well known descriptions of this ability in her reports of child artist, Nadia (15). Diagnosed with autism when she was six years old, Nadia possessed no language skills and poor comprehension, however, at the age of three and a half years she developed an amazing capacity to draw. This drawing ability apparently arose spontaneously, omitting the normal scribbling stage associated with children's normal drawing development (16). Without the benefit of training Nadia displayed the use of 
complex graphic strategies such as linear perspective, foreshortening, occlusion and proportioning, which are not usually apparent in artistic output until much later in life.

The artistic savant E.C. $(17,18)$ showed a noticeable attention to detail and a lack of global precedence in his artistic technique. Like Nadia, EC was able to reproduce highly detailed pictures with excellent perspective and perfect proportions, as well as an ability to draw images from unusual points of view. Also like Nadia, it was noted that E.C. never used an eraser to amend his drawings and was able to draw perfect lines and circles without the use of any drawing equipment. They noticed that when E.C. began to draw, using his normal rigid drawing routine, the orientation of the object to-be-drawn was often independent of the orientation of the sheet of paper. Though he primarily produced outline drawings, it was frequently observed that he began drawing with minor or secondary detail of the object and then progressed by adding contiguous elements, ignoring completely the 'visual-semantic' features, which are normally the target of an artist's impression, delineating the global nature of the model.

\section{Cognition and intelligence}

The prodigious nature of some of the talents displayed is startling when contrasted with the overall cognitive profile. This naturally brings into question traditional views of intelligence suggesting that a general processing capacity, $g$, governs cognition. The fact that individuals with either mental retardation or developmental disorders, such as autism, are capable of such extraordinary feats has been cited as evidence against this idea of a general intelligence and in support of the modular nature of intelligence $(11,19)$. Despite the apparent independence of a general factor on savant ability, IQ has been found to correlate with performance in a number of studies with savants. The interaction of ' $\mathrm{g}$ ' and modular talent has been modelled (19) with special reference to mental retardation, autism and savant talent.

\section{Autism Spectrum Disorder}

Although not all savants are given the diagnosis of autism it is the case that the majority, if not all, show many of the behaviours associated with autistic spectrum disorder. The diagnosis depends on behaviour alone, occurs in 6 in 1,000 children (20) and is characterised as showing a triad of impairments, including social 
understanding, imagination and communication as well as obsessive and repetitive interests and behaviours. Recent advances in our theoretical and biological understanding of autism (21) have highlighted its complexity. There are several cognitive theories of autism and it is not within the scope of this paper to discuss them here, however both Frith's theory of weak central coherence (22) and the perceptual hierarchical theory described by Mottron (e.g. 23) are particularly relevant to savant syndrome.

Amongst children with autism about 1 in 10 have been described as displaying special talents or abilities; this may be somewhat similar to the incidence of talent amongst normally developing children.

\section{Implicit learning and memory}

Implicit learning is phylogenetically an older form of learning than explicit learning and shows little variation as a function of age or IQ. Implicit learning of material can build up a complex but organised knowledge network, independent of cognitively mediated explicit processing of material, as for example is seen in the acquisition of language grammars. Calendar calculators may implicitly learn associations and use dates as "benchmarks" which are linked to form an association network of knowledge, from which emergent regularities can be derived. Such networks may then embody calendar information and be used to calculate $(8,7)$, but they could also embody other types of information. For instance a similar system, using pitches as "benchmarks" instead of dates, is proposed to underlie the development of the musical savant's internal, hierarchically organised, musical knowledge network (5). Such a system would clearly require extremely good pitch naming and memory as possessed by savant musicians.

Implicit processing and organization of material may link the notion of talent and the effects of practice, with the former being a basic determinant of the latter. Connectionist accounts have not been wholly successful (24) but indicate a way that an instant-based knowledge base can be constructed to allow structured regularities in the material to emerge. It cannot be chance alone that savant talents seem to share complex but rule-bound knowledge domains such as language (grammar), musical grammar, calendar and numerical calculation as well as complex graphic talents 
particularly at the level of perspective skills where visual-perceptual transformations based on complex geometries are critical.

\section{Cognitive theories of savant syndrome}

There have, over the years, been a number of attempts to conceptualise the outstanding feats of these individuals. Early accounts focussed on sensory deprivation, compensation and abstraction deficits. While many of these accounts have been widely disregarded over time, others have formed the basis for the contemporary theories and reviews $(2,5,12,25)$. Here the focus has been on those connected to the issue of talent.

\section{Extended practice}

Howe, Davidson \& Sloboda (3) maintain that talent is simply a manifestation of (obsessive) interest and a high degree of practice, found amongst many in the normal as well as the savant population. Certainly this might help account for the high rate of savant ability found in individuals with autism, since this is a characteristic.

Nevertheless, while it is likely that savants do spend a disproportionate amount of time practising this explanation alone cannot account for the savant phenomenon. It fails to explain sufficiently the manifestations of 'talent', which occur from a very early age and in the absence of training. Also, it has been suggested that the obsessional activity associated with savants is qualitatively different from that practised by non-autistic experts. Trehub and Schellenberg (26) refer to a three-factor model of high ability (27), arguing none of the factors; goal setting, evaluation and feedback, are evident in savant activity. It appears then that savants practice because they enjoy the activity rather than to improve their performance, practice is necessary in the attainment of high-level ability, but it is not by itself sufficient (28) though this has been disputed (29).

\section{Rote memory}

A number of explanations of savant ability have focussed on the outstanding memory and the capacity of savant artists to produce complex artistic outputs, in some cases several months after seeing the initial image $(6,15,30)$. Yet certainly the renditions are not 'eidetic' or $100 \%$ accurate but show some generative qualities. In terms of 
date calculation rote memory explanations of calendar calculating skills have been considered. The outstanding date calculation skills of the famous twins George and Charles (6), although referred to in terms of the rote memorization of the calendar based on endless practice, may simply have been indicative of implicit learning (as argued above). While published formulas and algorithms exist for calculating dates and can be found in encyclopaedia and almanacs, it is widely accepted that savant calendrical calculation is unlikely to be based on such detailed and complex preformulated methods. Not only is it implausible that learning-disabled individuals have access to the relevant publications, more importantly, the mastery of such formulas requires a level of reading comprehension, memory, and numerical ability clearly beyond that of most savants. Savant date calculation may be associated with visual imagery/memory in some cases although the study of a congenitally blind calendrical calculator, with no access to a Braille calendar, appears to rule out visual imagery as a universal explanation. Anchor dates may be rote learnt and used to 'key off' a counting strategy but this would still require a knowledge of the systematic changes within the calendar.

Rote memorization is not the same process as implicit learning, yet they can be linked and together they form a tenable explanation of the development of the underlying knowledge systems. Thus, practice and rote memorisation may allow implicit learning of complex and organised knowledge networks. The key characteristic of such a system is that it affords the basis of an essentially generative, even creative, process. Far from 'rote', the output of savant talent is rarely an exact replica of the original input $(30,7)$.

\section{Weak coherence}

Early research into autism had focussed on the social-cognitive characteristics yet a striking feature of the disorder is that the deficits are frequently accompanied by some enhanced abilities (22). Frith (22) and later Happé (31) outlined an account of autism that could explain the spiky profile and argued for the expression of a weak (or inhibited) influence of 'central coherence'. It is an account of the cognitive architecture underlying autism. The theory proposes that the normal drawing together of diverse information in order to construct higher-level meaning is disrupted. Instead processing, perceptual and conceptual, is piecemeal and attention to local parts occurs 
at the cost of attention to global, gestalt-like processes. Weak coherence has been demonstrated at several levels: perceptual, visuo-spatial constructional and verbal semantic. An example of weak coherence in autism can be illustrated by the unexpectedly high level of performance on a block design test (Wechsler Intelligence Scale) or an embedded figures test both of which depend on the successful inhibition of gestalt-like processes, in favour of specific focus on (perhaps) non-meaningful elements.

The theoretical position put forward by Mottron and associates (e.g. 23) have some features in common with Frith but they suggest that there is a multi-modal abnormality in the integration of parts and whole in autistic talented performance. In their account they refer to a deficit in the way perceptual material is hierarchically processed. They argue that while there is a 'local bias', there may not be a deficit in global organisation. Processing at the local level, usually considered less salient, has equal weight to global processes.

\section{Weak coherence: a predisposition for the development of talent}

The problem for psychologists is that talent is a vague concept and one that is defined within context and culture. Nevertheless, linking a cognitive style such as that described as weak coherence to talented performance in general terms may be helpful. Weak coherence may be a decisive characteristic (as is argued for autism) or an adaptive strategy amongst all individuals but especially important in the development of talent. In order to develop their talents individuals may, in essence, need to inhibit automatic, conventional coherence that serves to limit generative thinking and retain instead the accurate segments of perception. While weak coherence has been linked to thinking style in physicists and engineers (32) as well as artists (33), the experimental evidence has generally been limited to comparing autistic individuals with and without talents (e.g. 34). For example, children and adults gifted in art, show superior skills on traditional tests of weak coherence, also savant artists were better able than autistic control participants at reconstituting a visual display in the form of a picture puzzle as well a showing superior performance on block design and embedded figures tests. Talent then may be linked to a way of thinking that retains 
segments or elements of domain-specific knowledge protecting them from normal cohering and integrative processes.

In terms of musical processing, the absolute pitch abilities of musical savants and the musical processing of high functioning children with autism argue for a 'weak coherence' pattern of advantage in the musical domain analogous to that found in the visual domain (35). The ability to identify individual notes from chords or retain pitch in memory without the need for a reference note may be dependent on having weak coherence. Furthermore such reasoning can be used to understand calendar calculating ability (8), where the elements of the calendar, i.e. day of the week, day, month and year need to be retained individually and not treated simply as a single representation along with lightening mental calculators, where speeded factorisation ability, i.e. the breaking down larger numbers to their constituent factors, is critical. Wim Klein, the famous mental calculator, for example, gives a flavour of such segmented (weak coherence) processing style when he remarked "it's not the same for you is it? Numbers are friends to me. Take the number 3844. I say Hi 62, squared" (36).

The weak coherence account of savant ability is useful in that it not only provides some reasoning for the prevalence of talented performance in autism, but may also be linked to the manifestation of superior ability, in certain domains, in the normal population. 


\section{References}

1. Down, J. L. (1987). On some mental afflictions of childhood and youth. London: Churchill.

2. Treffert, D. A. (1989). Extraordinary people. Understanding "idiotsavants". New York: Bantam.

3. Howe, M. J. A., Davidson, J. W., \& Sloboda, J.A. (1998). Innate talents: Reality or myth? Behavioural and Brain Sciences, 21, 399-342.

4. Rutter, M. (1998). What can we learn from highly developed skills? Commentary. Behavioural and Brain Science, 21, 422-423.

5. Miller, L. (1999). The savant syndrome: Intellectual impairment and exceptional skill. Psychological Bulletin, 125, 31-46.

6. Sacks, O. (1995). An anthropologist on mars. London: Picador.

7. Pring, L. and Hermelin, B. (2002) Numbers and letters: Exploring an autistic savant's unpractised ability. Neurocase 8, 330-337.

8. Heavey, L., Hermelin, B., \& Pring, L. (1999). A date to remember: The nature memory in savant calendrical calculators. Psychological Medicine, 29, 145-160.

9. Green,A.J.K. \& Gilhooly, K.J. (1992) Empirical advances in expertise research. In M.T. Keane \& Gilhooly, and K.J. Gilhooly (Ed.) Advances in the psychology of thinking.: UK, London Harvester, Wheatsheaf.

10. Anderson, M, O'Connor, N. \& Hermelin, B. (1998) A specific calculating ability. Intelligence. 26(4):383-403.

11. Smith, N. \& Tsimpli, I.M. (1995) The Mind of a Savant: Language, Learning and Modularity. Malden, US: Blackwell's Publishers.

12. Hermelin, B. (2001). Bright splinters of the mind. London: Jessica Kinsgley.

13. Dowker, A., Hermelin, B., \& Pring, L. (1996). A savant poet, Psychological Medicine, 26, 913-934.

14. Rhodes. N., Dowker, A., \& Claridge, G. (1995) Subject matter and poetic device in psychotics' poetry. British Journal of Medical Psychology, 68(4) 311-321.

15. Selfe, L. (1977). Nadia: A case of extraordinary drawing ability in an autistic child. London: Academic Press.

16. Thomas, G. V., \& Silk, A. M. J. (1990). An Introduction to the Psychology of Children's Drawings. New York: Harvester Wheatsheaf. 
17. Mottron, L. \& Belleville, S. (1993). A study of perceptual analysis in a highlevel autistic subject with exceptional graphic abilities. Brain and Cognition, 23, 279-309.

18. Mottron, L., \& Belleville, S. (1995). Perspective production in a savant autistic draughtsman, Psychological Medicine, 25, 639-648.

19. Anderson, M. (1998). Mental retardation general intelligence and modularity. Learning and Individual Differences, 10, 159-178.

20. Charman, T. (2002) The prevalence of autism spectrum disorders: Recent evidence and future challenges. European Child Adolescent Psychiatry 11:249-56.

21. Lord, C. \& Bailey, A. (2002). Autism spectrum disorders. In M. Rutter \& E. Taylor (Eds.) Child and adolescent psychiatry (pp. 636-664). Oxford: Blackwell Science.

22. Frith, (2003) Autism: Explaining the Enigma ( $2^{\text {nd }}$ Edition) Blackwells:Oxford.UK.

23. Mottron, L, Burack, J. Iarocci, G, Belleville, S and Enns, J. (2003) Locally oriented perception with intact global processing among adolescents with high-functioning autism: Evidence from multiple paradigms. Journal of Child Psychology and Psychiatry. 44 (6): 904-913.

24. Norris, D. (1990) How to build a connectionist idiot (savant). Cognition 35:277-291.

25. Heaton. P, and Wallace, G.L. (2004) The savant syndrome. Journal of Child Psychology and Psychiatry, Vol. 45. No. 5. pp.899-911.

26. Trehub, S. E., \& Schellenberg, E. G., (1998). Cultural determinism is no better than biological determinism. Brain and Behavioural Sciences, 21, 427428.

27. Lehmann, A. C. (1997). Acquisition of expertise in music: Efficiency of deliberate practise as a moderating variable in accounting for sub-expert performance. In J. A. Sloboda \& I Deliege Perception and cognition of music. NJ.: Erlbaum.

28. Winner, E. (2000) Giftedness: Current theory and research. Current Directions in Psychological Science, Vol 9. No 5. p153-156.

29. Ericsson, K.A. (2003) Exceptional memorizers: made, not born. Trends in Cognitive Neuroscience, Vol 7, No 6. p223-225. 
30. Hermelin, B., \& Pring, L., with Buhler, M., Wolff, S., \& Heaton, P. (1999). A visually impaired savant artist: Interacting perceptual and memory representations. Journal of Child Psychiatry and Psychology, 7, 1129-1139.

31. Happé, F. G. E. (1999). Autism: Cognitive deficit or cognitive style? Trends in Cognitive Science, 3, 216-222.

32. Wheelwright, S. \& Baron-Cohen, S. (2001) The link between autism and skills such as engineering, maths, physics and computing. Autism, 5(2): 223227.

33. Getzels, J.W. \& Csikszentmihalyi, M. (1976) The Creative Vision: A Longitudinal Study of Problem Finding in Art. New York: John Wiley.

34. Pring, L., Hermelin, B., \& Heavey, L. (1995). Savants, segments, art and autism. Journal of Child Psychology and Psychiatry, 36, 1065-1076.

35. Heaton, P., Hermelin, B., \& Pring, L. (1998). Autism and pitch processing: A precursor for savant ability? Music perception, 15, 291-305.

36. Smith, S, B. (1983) The Great Mental Calculators. New York: Columbia University Press p5. 